\title{
A case of thyroid storm with cardiac arrest
}

This article was published in the following Dove Press journal:

International Medical Case Reports Journal

8 May 2014

Number of times this article has been viewed

Yutaka Nakashima'

Tsuneaki Kenzaka²

Masanobu Okayama ${ }^{3}$

Eiji Kajii ${ }^{3}$

'Department for Support of Rural Medicine, Yamaguchi Grand

Medical Center, ${ }^{2}$ Division of

General Medicine, Center for

Community Medicine, Jichi Medical

University School of Medicine,

Shimotsuke, Japan; ${ }^{3}$ Division of

Community and Family Medicine,

Center for Community Medicine,

Jichi Medical University School of

Medicine, Shimotsuke, Japan
Correspondence: Tsuneaki Kenzaka

Division of General Medicine,

Center for Community Medicine,

Jichi Medical University School of

Medicine, 33II-I Yakushiji, Shimotsuke,

Tochigi 329-0498, Japan

Tel $+8 \mid 285587394$

Fax +8I 285440628

Email smile.kenzaka@jichi.ac.jp
Abstract: A 23-year-old man became unconscious while jogging. He immediately received basic life support from a bystander and was transported to our hospital. On arrival, his spontaneous circulation had returned from a state of ventricular fibrillation and pulseless electrical activity. Following admission, hyperthyroidism led to a suspicion of thyroid storm, which was then diagnosed as a possible cause of the cardiac arrest. Although hyperthyroidism-induced cardiac arrest including ventricular fibrillation is rare, it should be considered when diagnosing the cause of treatable cardiac arrest.

Keywords: hyperthyroidism, ventricular fibrillation, treatable cardiac arrest, cardiac arrest, cardiopulmonary arrest

\section{Introduction}

There are few reports on cases of thyroid storm-induced cardiac arrest including ventricular fibrillation. ${ }^{1-5}$ We report a case of undiagnosed hyperthyroidism that was diagnosed as a result of thyroid storm-induced cardiac arrest.

\section{Case presentation}

The subject was a 23-year-old Japanese man with no abnormalities identified on examination and no particular medical history. Two weeks prior to onset of cardiac arrest, he noticed slight fever, coughing, loss of appetite, and weight loss of $3 \mathrm{~kg}$. He did not have symptoms such as nausea, vomiting, or diarrhea. While jogging, the patient became aware of back pain and lost consciousness. A bystander immediately administered basic life support. Then, emergency medical technician-paramedics continuously administered cardiac pulmonary resuscitation using an automated external defibrillator to the subject, who was thereafter transported by ambulance to our hospital, Yamaguchi Grand Medical Center.

At the time of transfer to the hospital, the blood pressure of the subject could not be measured. An electrocardiogram (ECG) monitor indicated that his heart rate was $30 \mathrm{bpm}$ (pulseless electrical activity) (Figure 1). In addition, his body temperature was $37.3^{\circ} \mathrm{C}$ and he had a Glasgow coma scale score of E1M1V1 (no eye opening, no verbal response, no motor response). Physical examination revealed swelling of the thyroid gland on the anterior side of the neck; however, there were no signs of jaundice or peripheral edema. In addition, there were no signs of exophthalmos, finger tremor, loss of hair, or nail lesions. Because of pulseless electrical activity, cardiac arrest was diagnosed using an ECG, and administration of medication (epinephrine and atropine) led to ventricular fibrillation (Figures 2 and 3). As a result, defibrillation 


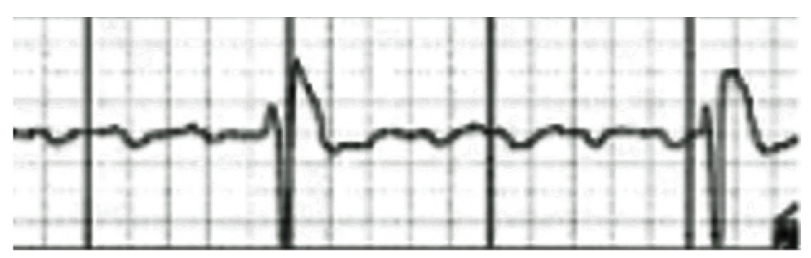

Figure I Electrocardiogram at the time of transfer to the hospital. There was pulseless electrical activity.

was administered using a direct current (DC) type 360-J monophasic defibrillator (Nihon Kohden Corporation, Tokyo, Japan) and the sinus rhythm was restored. Nonetheless, heart rate and breathing sounds were normal.

The laboratory findings were as follows: a white blood cell count of $13,800 / \mu \mathrm{L}$; hemoglobin, $12.0 \mathrm{~g} / \mathrm{dL}$; platelets, $434,000 / \mu \mathrm{L}$; C-reactive protein, $0.2 \mathrm{mg} / \mathrm{dL}$; aspartate aminotransferase, $51 \mathrm{IU} / \mathrm{L}$; alanine aminotransferase, $74 \mathrm{IU} / \mathrm{L}$; lactic dehydrogenase, $217 \mathrm{IU} / \mathrm{L}$; creatine kinase $61 \mathrm{IU} / \mathrm{L}$; creatine kinase MB $46 \mathrm{IU} / \mathrm{L}$; troponin $\mathrm{T},<0.05 \mathrm{ng} / \mathrm{mL}$; blood urea nitrogen, $16.4 \mathrm{mg} / \mathrm{dL}$; creatinine, $0.81 \mathrm{mg} / \mathrm{dL}$; blood glucose, $77 \mathrm{mg} / \mathrm{dL}$; sodium, $143 \mathrm{mmol} / \mathrm{L}$; potassium, $5.8 \mathrm{mmol} / \mathrm{L}$; chloride, $97 \mathrm{mmol} / \mathrm{L}$; calcium, $9.2 \mathrm{mg} / \mathrm{dL}$; arterial blood gases $\left(\mathrm{FiO}_{2}: 100 \%\right.$, timing of return of spontaneous circulation and post-tracheal intubation); $\mathrm{pH} 7.53 ; \mathrm{PaCO}_{2}$ $30.8 \mathrm{mmHg} ; \mathrm{PaO}_{2} 184 \mathrm{mmHg}$; and $\mathrm{HCO}_{3} 11.4 \mathrm{mEq} / \mathrm{L}$.

Chest radiography revealed no congestion or pneumothorax in the lung field. After the sinus rhythm improved, an ECG revealed no significant changes in ST-T or QT interval prolongation (Figure 4). In the echocardiography results, there was no cardiac wall motion dyssynchrony suggestive of ischemic heart disease, and the ejection fraction was $70 \%$. There were no right side of the heart findings indicative of cardiac tamponade and thromboembolism. Thyroid ultrasound imaging showed that the parenchyma was marginally irregular and heterogeneous with rich blood flow.

On examination of thyroid function, the following findings were obtained: thyroid-stimulating hormone (TSH) level: $<0.005$ (reference range: $0.24-3.72$ ), free thyroxine $\left(\mathrm{T}_{4}\right)$ level: 5.03 (reference range: $0.94-1.52$ ), free triiodothyronine $\left(\mathrm{T}_{3}\right)$ level: $>30.00$ (reference range: $2.01-3.72$ ), TSH receptor

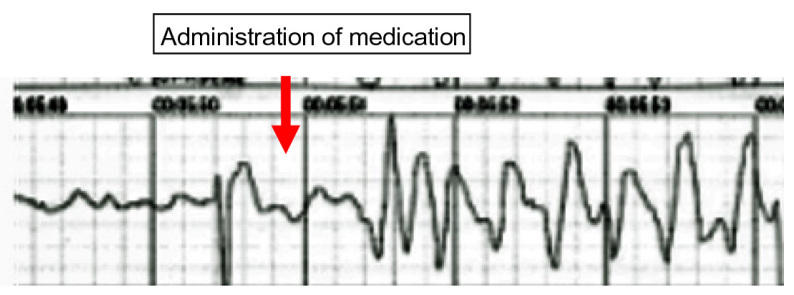

Figure 2 An electrocardiogram registered by the automated external defibrillator. Pulseless electrical activity turned into ventricular fibrillation.

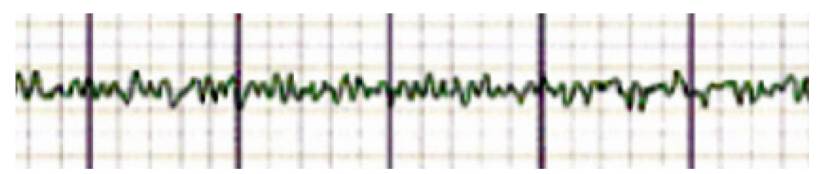

Figure 3 An electrocardiogram after administration of medication. Ventricular fibrillation was observed.

antibody: $30.2 \%$ (reference values: $<15$ ), and TSH-stimulating receptor antibody: $146 \%$ (reference values: $<180$ ).

After spontaneous circulation was returned, the reduced level of consciousness persisted and artificial respiration and cerebral hypothermia were administered. Hyperthyroidism-induced thyroid storm was strongly suspected and the patient was treated with thiamazole $60 \mathrm{mg} / \mathrm{day}$, inorganic iodine (iodine solution $150 \mathrm{mg} /$ day), hydrocortisone $300 \mathrm{mg} /$ day, and metoprolol tartrate (beta-blocker) $120 \mathrm{mg} /$ day for 2 weeks. After the initial 2 weeks, thiamazole $60 \mathrm{mg} /$ day and metoprolol tartrate (beta-blocker) $120 \mathrm{mg}$ /day were taken.

On day 22 of hospitalization, the subject was weaned from the artificial respirator; however, hypoxic encephalopathyinduced higher cerebral dysfunction persisted.

On day 30 of hospitalization, follow-up testing revealed that free $\mathrm{T}_{4}$ and free $\mathrm{T}_{3}$ levels had returned to normal (free $\mathrm{T}_{4}$ level: 1.46 and free $\mathrm{T}_{3}$ level: 3.43 ), but TSH suppression persisted (TSH <0.005). Because of higher cerebral

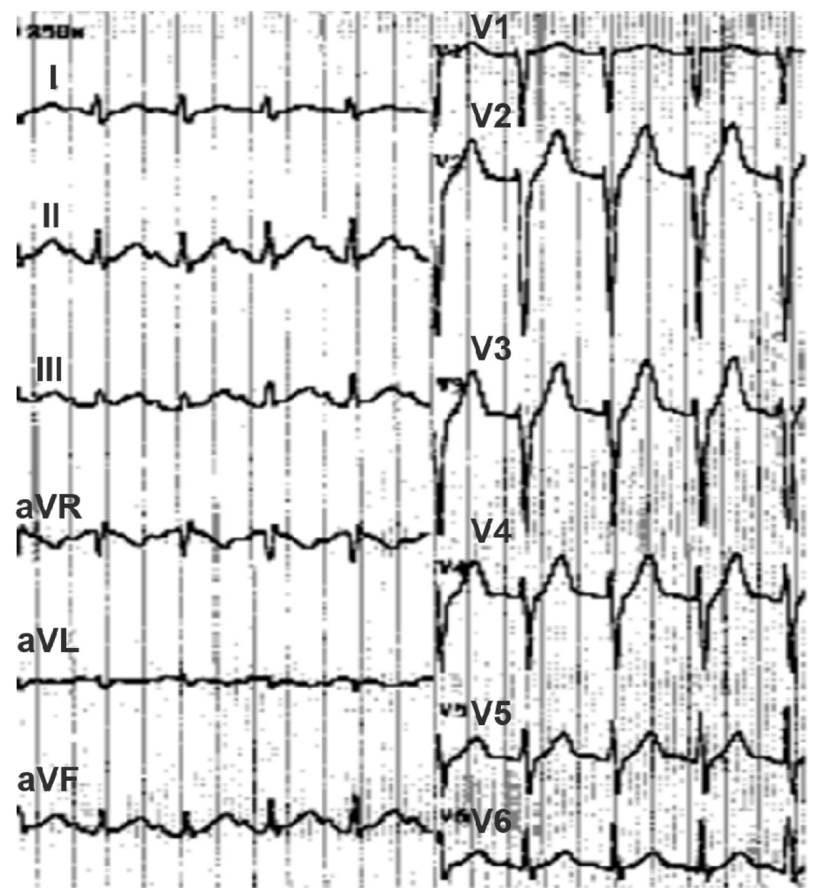

Figure 4 Twelve-lead resting electrocardiogram after defibrillation. Heart rate was $140 \mathrm{bpm}$ with sinus tachycardia, and the QT interval was 415 milliseconds. There were no significant changes in the ST-T interval.

Abbreviations: aVR, augmented vector right; aVL, augmented vector left; aVF, augmented vector foot. 
dysfunction, coronary angiogram and magnetic resonance imaging (MRI) of the heart were not performed in accordance with the wishes of his family. On day 55, the subject was transferred to another hospital for long-term medical care. TSH level was 0.14 at the time.

At the present 1-year follow-up, no signs of recurrent ventricular fibrillation or other cardiac arrest rhythms have been observed in the other hospital in which the patient is receiving long-term medical care.

\section{Discussion}

Our case subject was diagnosed with TSH receptor antibodypositive hyperthyroidism, otherwise known as Basedow's disease.${ }^{6,7}$ Arrhythmia due to hyperthyroidism often manifests itself as sinus tachycardia, atrial fibrillation, or ventricular tachycardia,${ }^{8}$ but rarely as a cardiac arrest including ventricular fibrillation. ${ }^{1-5}$ A cardiac arrest is rarely led by hypokalemia. ${ }^{3}$ In contrast, Ueno et al, ${ }^{1}$ Ando et al, ${ }^{4}$ and Jao et $\mathrm{al}^{5}$ described cases of a cardiac arrest with a thyroid storm where the patients did not have hypokalemia or other signs of a complicating disorder.

In this case, congenital coronary artery anomalies, myocarditis, drug intoxication, and anaphylaxis from an insect bite were considered as the cause of cardiac arrest. Because serum creatine kinase, 12-lead ECG, and echocardiographic evaluation did not change over time, it is unlikely that our patient had myocarditis. Because of the absence of a history of drug abuse and the lack of injection scars, bite marks, or a skin rash, it is unlikely that drug intoxication or anaphylaxis from an insect bite were involved. Because a coronary angiogram and MRI of the heart were not performed, the patient might have congenital coronary artery anomalies. Nonetheless, an additional factor was necessary for the sudden cardiac arrest to occur, even if the patient has congenital heart disease.

In the present case, there was no underlying heart disease according to echocardiography. Moreover, the treatment of hyperthyroidism prevented recurrence of ventricular fibrillation and other cardiac arrest rhythms. This observation led to the suspicion of a thyroid storm, which was then diagnosed as a possible cause of the cardiac arrest.

It has been reported that a thyroid storm may affect the heart owing to early repolarization and coronary artery spasms; in addition, a smoking habit can also contribute to early repolarization and coronary artery spasms. ${ }^{4}$ The effects of thyroid hormones on the heart are as follows: accelerated protein and messenger RNA synthesis in myocardial cells; $\mathrm{Na}-\mathrm{K}$ adenylpyrophosphatase (ATPase) hyperactivity; increased $\mathrm{Ca}^{2+}$ transport; an increased number of $\beta$-receptors; a reduced refractory phase; and a low stimulus threshold. ${ }^{8}$

Our subject had a score of 70 points (temperature, 5 ; central nervous system effects, 30; cardiovascular dysfunction, 25; and precipitant history, 10) according to the diagnostic criteria (Table 1); these data were indicative of a thyroid storm.

A thyroid storm is a rare condition affecting $1 \%-2 \%$ of patients with hyperthyroidism. It is a life-threatening condition and is reported to have a fatality rate of $50 \%-90 \%$ if left untreated or $20 \%-30 \%$ if treated. ${ }^{9}$

Treatable causes of a cardiac arrest include the H's and T's, namely hypoxia, hypovolemia, hydrogen ion (acidosis), hypo- or hyperkalemia, hypothermia, toxins, tamponade

Table I Diagnostic criteria of a thyroid storm

\begin{tabular}{|c|c|c|c|c|c|}
\hline $\begin{array}{l}\text { Thermoregulatory } \\
\text { dysfunction }\end{array}$ & & $\begin{array}{l}\text { Central nervous } \\
\text { system effects }\end{array}$ & & $\begin{array}{l}\text { Cardiovascular } \\
\text { dysfunction }\end{array}$ & \\
\hline Temperature $\left({ }^{\circ} \mathrm{C}\right)$ & & Mild & 10 & Tachycardia & \\
\hline 37.2 to 37.7 & 5 & Agitation & & 99 to 109 & 5 \\
\hline 37.8 to 38.2 & 10 & Moderate & 20 & 110 to 119 & 10 \\
\hline 38.3 to 38.8 & 15 & $\begin{array}{l}\text { Delirium, psychosis, } \\
\text { extreme lethargy }\end{array}$ & & 120 to 129 & 15 \\
\hline 38.9 to 39.2 & 20 & Severe & & 130 to 139 & 20 \\
\hline 39.3 to 39.9 & 25 & Seizure, coma & 30 & $\geq 140$ & 25 \\
\hline$>40.0$ & 30 & & & Atrial fibrillation & 10 \\
\hline $\begin{array}{l}\text { Gastrointestinal-hepatic } \\
\text { dysfunction }\end{array}$ & & Heart failure & & $\begin{array}{l}\text { Precipitant } \\
\text { history }\end{array}$ & \\
\hline Moderate & 10 & Mild & 5 & Negative & 0 \\
\hline Diarrhea & & Pedal edema & & Positive & 10 \\
\hline Nausea/vomiting & & Moderate & 10 & & \\
\hline Abdominal pain & & Bibasilar rales & & & \\
\hline Severe & 20 & Severe & 15 & & \\
\hline Unexplained jaundice & & Pulmonary edema & & & \\
\hline
\end{tabular}

Notes: A score of 45 or higher is highly indicative of a thyroid storm; a score of $25-44$ supports the diagnosis; and a score below 25 makes a thyroid storm unlikely. Scoring system from Burch and Wartofsky. 
(cardiac), tension pneumothorax, pulmonary thrombosis, and coronary thrombosis. ${ }^{10}$ Although a hyperthyroidism-induced cardiac arrest is rare, it is a treatable arrhythmia.

Despite persistent higher cerebral dysfunction, our subject survived and exhibited no recurrence of ventricular fibrillation and other cardiac arrest rhythms because of the treatment of thyroid function. In the event of a cardiac arrest in the absence of the H's and T's, hyperthyroidism should be considered as another possible treatable cause.

\section{Conclusion}

We experienced a case of cardiac arrest associated with hyperthyroidism. In the event of cardiac arrest in the absence of a treatable cause (one of the H's and T's), hyperthyroidism should be considered as another potential treatable cause.

\section{Author contributions}

Yutaka Nakashima: manuscript editing.

Tsuneaki Kenzaka: management of the case, manuscript editing and correction.

Masanobu Okayama: clinical management of the case and revision of the manuscript.

Eiji Kajii: manuscript correction, editing of the captions for the illustrations.

All authors contributed to conception and design, acquisition of data, or analysis and interpretation of data, and read and approved the final version of the manuscript.

\section{Disclosure}

The authors declare that they have no conflicts of interest related to this work.

\section{References}

1. Ueno A, Yamamoto T, Sato N, Tanaka K. Ventricular fibrillation associated with early repolarization in a patient with thyroid storm. J Interv Card Electrophysiol. 2010;29(2):93-96.

2. Wei JY, Genecin A, Greene HL, Achuff SC. Coronary spasm with ventricular fibrillation during thyrotoxicosis: response to attaining euthyroid state. Am J Cardiol. 1979;43(2):335-339.

3. Boccalandro C, López-Penabad L, Boccalandro F, Lavis V. Ventricular fibrillation in a young Asian man. Lancet. 2003;361(9367):1432.

4. Ando T, Henmi T, Haruta D, et al. Graves' disease complicated by ventricular fibrillation in three men who were smokers. Thyroid. 2011;21(9):1021-1025.

5. Jao YT, Chen Y, Lee WH, Tai FT. Thyroid storm and ventricular tachycardia. South Med J. 2004;97(6):604-607.

6. Matthews DC, Syed AA. The role of TSH receptor antibodies in the management of Graves' disease. Eur J Intern Med. 2011;22(3): 213-216.

7. Burch HB, Wartofsky L. Life-threatening thyrotoxicosis. Thyroid storm. Endocrinol Metab Clin North Am. 1993;22(2):263-277.

8. Klein I, Ojamaa K. Thyroid hormone and the cardiovascular system. N Engl J Med. 2001;344(7):501-509.

9. Fisher JN. Management of thyrotoxicosis. South Med J. 2002;95(5): 493-505.

10. Neumar RW, Otto CW, Link MS, et al. Part 8: adult advanced cardiovascular life support: 2010 American Heart Association Guidelines for Cardiopulmonary Resuscitation and Emergency Cardiovascular Care. Circulation. 2010;122(18 Supp1 3): S729-S767.
International Medical Case Reports Journal

\section{Publish your work in this journal}

The International Medical Case Reports Journal is an international, peer-reviewed open-access journal publishing original case reports from all medical specialties. Previously unpublished medical posters are also accepted relating to any area of clinical or preclinical science. Submissions should not normally exceed 2,000 words or

\section{Dovepress}

4 published pages including figures, diagrams and references. The manuscript management system is completely online and includes a very quick and fair peer-review system, which is all easy to use. Visit $\mathrm{http}: / /$ www.dovepress.com/testimonials.php to read real quotes from published authors. 